\title{
Comportamiento estructural de la plaza de toros Monumental de Sevilla, en base a las pruebas de carga de 1917 y 1918, y su demolición en 1930
}

\author{
Structural behavior of the Monumental bullring in Seville, based on the load \\ tests in 1917 and 1918, and the demolition in 1930 \\ $\underline{\text { F. Carrasco }}^{(*)}$, J. Carrasco ${ }^{(*)}$
}

RESUMEN

La plaza de toros Monumental de Sevilla fue uno de los edificios de referencia en los primeros años del siglo XX en España. Se inauguró el 6 de junio de 1918 después de haber sufrido dos hundimientos, uno durante la ejecución en 1916 y otro durante las pruebas de carga efectuadas en 1917. Posteriormente el edificio fue sometido a una prueba de carga satisfactoria en 1918, que ofreció las oportunas garantías para autorizar su inauguración. En 1921 el gobernador decretó el cierre del edificio por supuestos problemas estructurales, siendo demolido en 1930 tras casi una década de olvido. En este trabajo se recopilan documentos dispersos en varios archivos, que permiten determinar que la prueba de carga de 1918 fue rigurosa y que el comportamiento de la estructura fue correcto, mostrando su solidez incluso durante la demolición.

Palabras clave: hormigón, Sestao, prueba de carga, plaza toros Monumental, Sevilla

\section{ABSTRACT}

The Monumental bullring in Seville was one of them buildings of reference in the first years of the century XX in Spain. It was opened the 6 of June of 1918 after having suffered two collapses, one during the execution in 1916 and another during the load test made in 1917. Later the building was subjected to a satisfactory load test in 1918 that offered the necessary guarantees to authorize the inauguration. In 1921 the Governor decreed the closure of the building by alleged structural problems, being demolished in 1930 after a decade of oblivion. In this work are collected documents scattered in several archives, that allow to determine that the load test of 1918 was rigorous and that the behavior of the structure was correct, showing its strength even during the demolition.

Keywords: concrete, Sestao, load test, Monumental bullring, Seville

Universidad Politécnica de Madrid. (España)

Persona de contacto/Corresponding author: fidel.carrasco@upm.es (F. Carrasco)

ORCID: https://orcid.org/oooo-0002-7224-1132. (F. Carrasco); http://orcid.org/oooo-0oo2-6307-3712 (J. Carrasco).

Cómo citar este artículo/Citation: Carrasco, F., Carrasco, J. (2018) Comportamiento estructural de la plaza de toros Monumental de Sevilla, en base a las pruebas de carga de 1917 y 1918, y su demolición en 1930. Informes de la Construcción, 70(549): e240. http://doi. org/10.3989/ic.16.124

Copyright: (C) 2018 CSIC. Este es un artículo de acceso abierto distribuido bajo los términos de la licencia de uso y distribución Creative Commons Reconocimiento 4.0 Internacional (CC BY 4.0). 


\section{INTRODUCCIÓN}

\subsection{Entorno histórico. Las plazas de toros monumentales}

En el ámbito taurino se conoce como la Edad de Oro del toreo, la época comprendida entre la alternativa de Juan Belmonte García, el 16 de septiembre de 1913 y el fallecimiento de José Gómez Ortega («Gallito» o «Joselito») el 16 de mayo de 1920. Ambos revolucionaron el toreo, pero Joselito fue más allá, preocupándose por todos los aspectos relacionados con la tauromaquia, incluyendo las plazas de toros. Afirma Ángel Sonseca Rojas (1), al referirse a la inauguración de la plaza de toros Monumental de Barcelona, que «Se trata del primer eslabón de una cadena de recintos planeada por " $\mathrm{Ga}$ llito". El menor de los Gómez Ortega mantiene la idea de construir plazas de toros con gran aforo, en las ciudades que lo permitan, y así abaratar los precios de las localidades y elevar los honorarios de los matadores». Bajo este impulso se concibieron las plazas de Logroño (1915), Barcelona (1916), Albacete (1918), Sevilla (1918) y Madrid (1934). «La plaza de Madrid en aquel entonces tenía una capacidad para 12.000 espectadores y José se acercó a José Espeliús y Anduaga, arquitecto y gran aficionado suyo, y juntos trazaron los planos y calcularon el presupuesto para una plaza de 26.00o localidades en la terminación de la calle de Alcalá»(2).

En Madrid, la construcción de Las Ventas conllevó la desaparición de la existente en la avenida de Felipe II (1874-1934), así como ésta trajo consigo la demolición de su precedente junto a la Puerta de Alcalá (1749-1874) (3). Es similar el caso de Barcelona, donde la Monumental surgió de ampliar la «Plaza del Sport» (1914). En cambio, en Sevilla se dio una circunstancia diferente, ya que la nueva plaza debería convivir con la existente, propiedad de la Real Maestranza de Caballería, cuya construcción fue amparada por los privilegios concedidos a la hermandad en 1730 (4). Las 23.0oo localidades de la Monumental (Figura 1) representaban una seria amenaza para la Maestranza, cuyo aforo supera escasamente las 12.500.

\subsection{La construcción de la Monumental}

El promotor José Julio Lissén contrató al arquitecto Francisco Urcola, especializado en el proyecto de edificios para espectáculos y en la técnica del hormigón armado. Entre sus obras figuran la Plaza de Toros del Chofre (1903) y el Teatro Victoria Eugenia (1912), ambos en San Sebastián, así como la Plaza de Toros de Pamplona (1922), de aspecto muy similar a la Monumental (27). El arquitecto sevillano José Espiau dirigió la obra, ejecutada por la Sociedad General de Cementos Portland de Sestao-Bilbao.

Las obras se iniciaron en 1916 (Figura 2), con la intención de inaugurarla el Domingo de Ramos de 1917. Las pruebas de carga previas a la inauguración produjeron el colapso de parte de la estructura, lo que obligó a aplazarla hasta 1918.

Este edificio fue uno de los más representativos en los primeros años del s.XX en España, formando parte de la exposición «Hormigón Armado en España 1893-1936» (5). A pesar de su importancia, apenas existe documentación.

\subsection{Sistema constructivo empleado. La Poutre Dalle}

Los inicios del hormigón armado en España se basan en sistemas de patentes, asunto abordado con detalle en dos trabajos

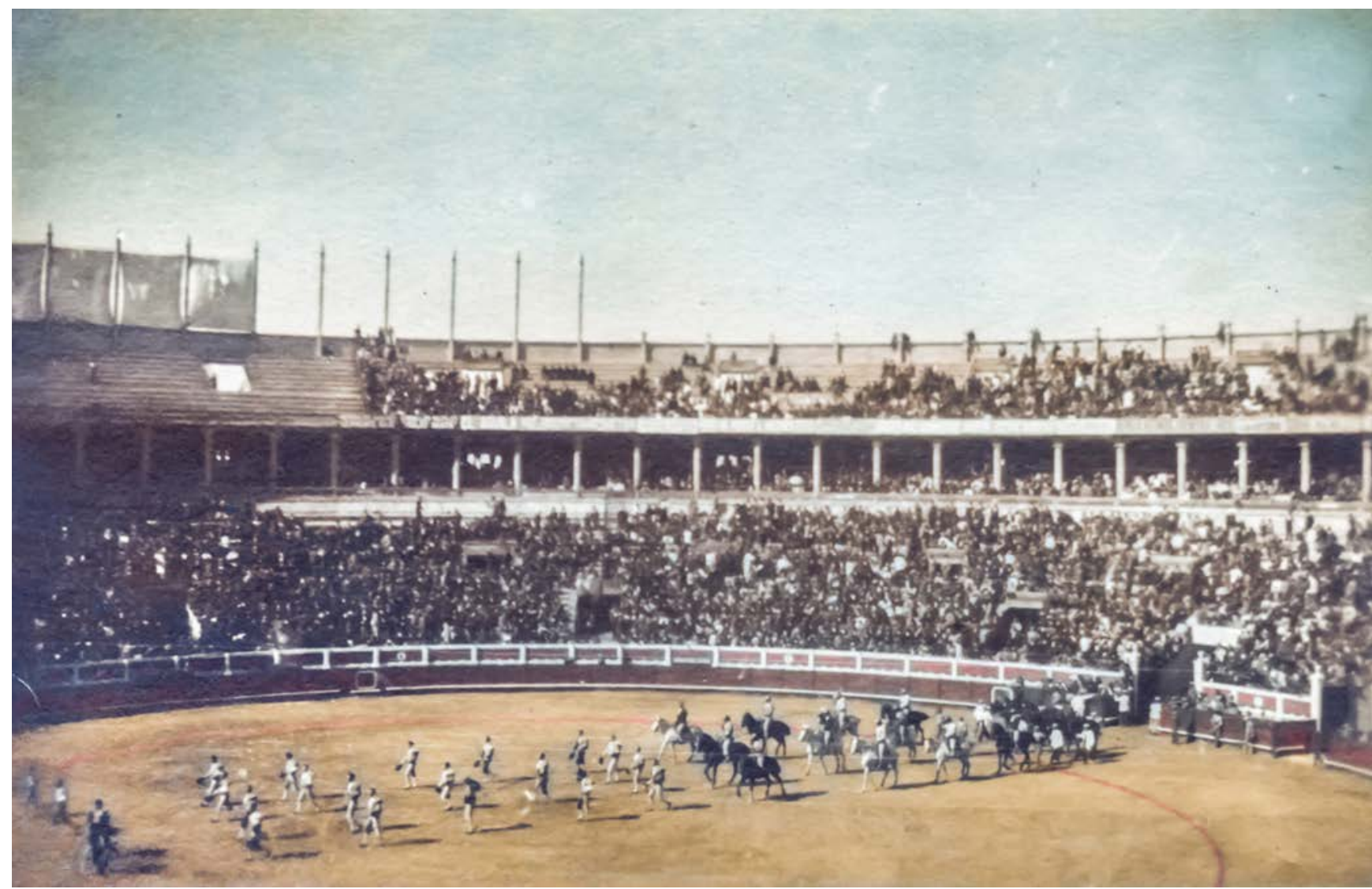

Figura 1. Plaza de toros Monumental de Sevilla. Blanco y negro, papel 6,5 cm x 4,5 cm. Colección de los autores. 


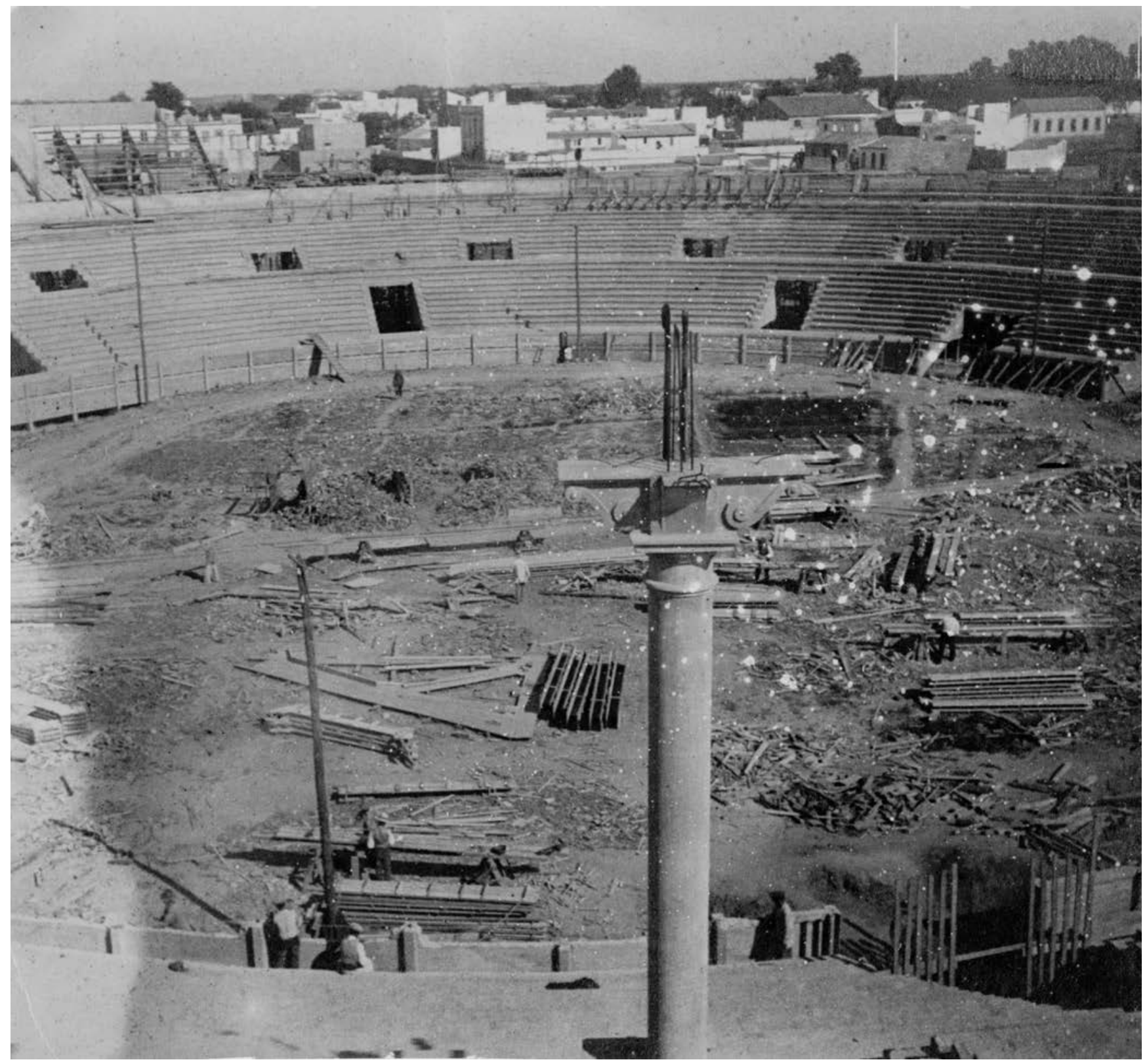

Figura 2. Construcción de la Monumental de Sevilla. Fundación FIDAS, Archivo Espiau, ref.: 2/00095 E02/1.

dedicados a sendos edificios en los que intervino la Compañía de Sestao: la Alhóndiga de Bilbao (6) y la cubierta del Tercer depósito del Canal, en Madrid (7).

La Compañía de Hormigones de Sestao surgió de la unión del industrial francés Eugenio Grimal y el ingeniero francés Joseph Blanc, introductor en España de la patente Poutre Dalle, caracterizada por el enlace entre forjados y vigas (8). Las aplicaciones del sistema aparecen en un documento (9) en el que se incluyen algunas figuras que ilustran sobre el modo de construir elementos planos, en los que las armaduras de vigas y viguetas se elaboraban disponiendo una barra de acero en la zona comprimida de la sección y dos en la traccionada. Estas barras se unían con alambres colocados a modo de estribos (Figura 3.1) o formando una celosía de alambre (Figura 3.4). Para otros casos, la aplicación debía adaptarse en base a la experiencia de los técnicos y constructores.

El arquitecto Urcola fue autor del proyecto y director de obra en la plaza de toros de Pamplona, muy similar a la Monu- mental de Sevilla. En el Archivo de la Casa de Misericordia disponen de algunos planos que permiten comprobar que los armados de vigas se disponen con una barra en la parte comprimida y dos barras en la zona traccionada, unidas con alambres en forma de estribo. En la cara inferior de los elementos superficiales se disponen 7 barras de $5 \mathrm{~mm} / \mathrm{m}$ en cada sentido (Figura 4). Teniendo en cuenta que se trata del mismo arquitecto que previamente construyó la Monumental, cabe pensar que los armados de aquella serían similares a los descritos.

\section{PRUEBAS DE CARGA EN LA PLAZA DE TOROS MONUMENTAL DE SEVILLA}

La plaza de toros Monumental fue objeto de dos pruebas de carga, una en 1917, que finalizó con el hundimiento de al menos una cuarta parte del edificio y otra en 1918. Previamente la plaza había sufrido otro hundimiento de consideración en 1916, durante la construcción, aparentemente como consecuencia de un temporal y de haber desencofrado antes de 


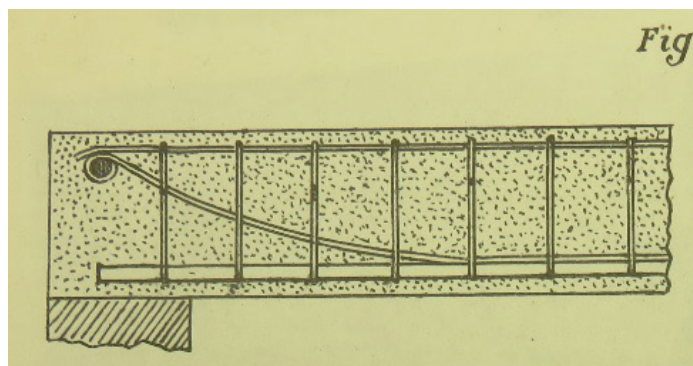

Fig. 2

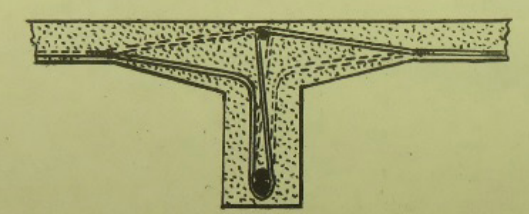

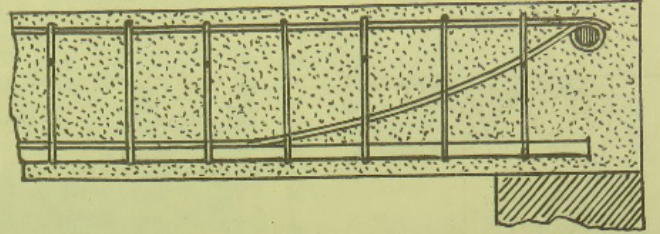

Fig. 3

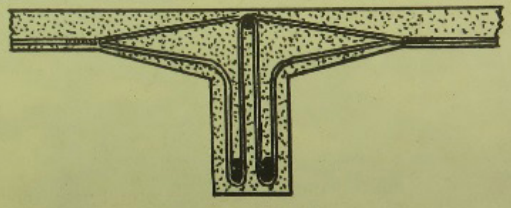

Fig. 4
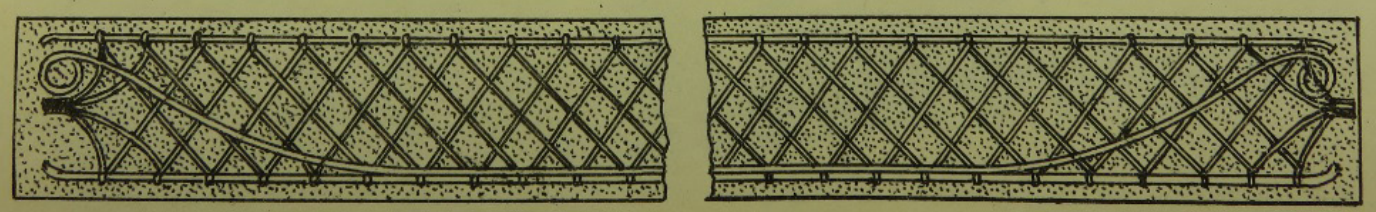

Figura 3. Dibujos de la «Nota sobre las construcciones de hormigón armado. La Poutre Dalle. Sistema Blanc.» publicada por la Compañía de Sestao en 1902.

\section{PIDNA THNIDII)(DS}

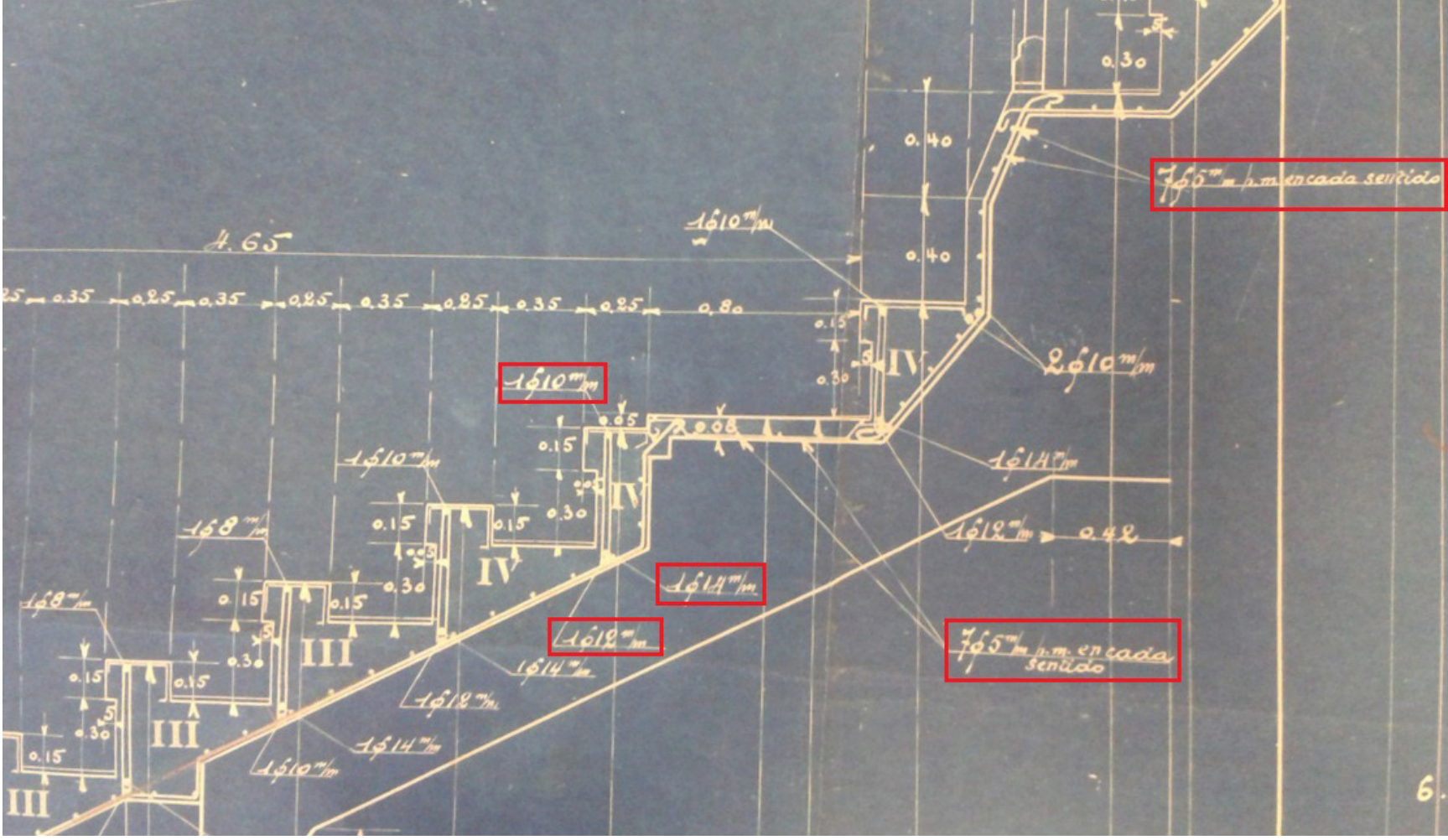

Figura 4. Detalle de la sección estructural de la plaza de toros de Pamplona. Los recuadros en rojo se han añadido para resaltar los armados. Archivo Casa de Misericordia. Plaza de Toros de Pamplona. 
tiempo (10). Se analizan a continuación ambas pruebas, comentando previamente esta práctica en la época.

\subsection{Las pruebas de carga a principios del siglo $\mathrm{XX}$}

En la segunda década del siglo XX el empleo del hormigón armado empezó a hacerse extensivo. Aunque no había una norma obligatoria en España, existían las «Instrucciones reglamentarias para el empleo del cemento armado», del Laboratorio del Material de Ingenieros, aprobadas en 1912 (11). Dado que algunos aspectos sobre el comportamiento del hormigón armado aún no se conocían o no se encontraban totalmente consolidados, propiciando que cada constructor desarrollara su propio «sistema», las administraciones solían recurrir a la realización de pruebas de carga para comprobar la seguridad.

Las pruebas de carga se contemplaban en las «Instrucciones reglamentarias para el empleo del cemento armado» en los artículos 32 a 39. Se indicaba que debían realizarse entre un mes y medio y dos meses después de finalizar la obra (Art. 32). También se indicaba que las cargas debían ser de 1,5 veces del valor de la sobrecarga considerada en proyecto, de modo que la estructura se viera sometida durante al menos veinticuatro horas a una carga $\mathrm{p}+1,5 \mathrm{p}^{\prime}$, siendo $\mathrm{p}$ el peso propio y $\mathrm{p}^{\prime}$ la sobrecarga (Art. 33). El modo de realizar la prueba consistía en comprobar que la carga del ensayo no produjera deformaciones permanentes superiores al 30 por 100 de las calculadas en proyecto. La medición debería realizarse «a intervalos fijos hasta que permanezcan invariables, lo cual deberá suceder, próximamente a las veinte horas de colocada la carga» (Art. 35 y 36). El propio Urcola lo pondría en práctica en las pruebas de carga de la plaza de toros de Pamplona, según consta en un certificado emitido el 24 de junio de 1922, que se conserva en el Archivo de la Casa de Misericordia.

\subsection{Prueba de carga de 1917 , realizada por técnicos nombrados por la Junta Provincial de Espectáculos}

La inauguración de la Monumental estaba prevista para el 1 de abril de 1917. Con tal fin el representante de la propiedad visitó al gobernador a finales de marzo, para que fijase la fecha de inspección del edificio por la Junta Provincial de Espectáculos. El 26 de marzo se produjo la visita de la Junta, formada por varias personas entre las que se encontraban los arquitectos provincial y municipal, Antonio Gómez Millán y Juan Talavera Heredia respectivamente, así como el Ingeniero Jefe de Obras Públicas de la provincia Félix Ramírez Doreste (Figura 5). Los dos primeros eran compañeros y amigos de José Espiau, lo que inicialmente supuso una tranquilidad para éste a la hora de efectuar las pruebas, pero acabó por transformarse en varios años de suspensión de la amistad con Juan Talavera (12). La propiedad se opuso a autorizar las pruebas con la presencia de los Sres. Ramírez Doreste y Gómez Millán, por no formar parte de la Junta Provincial de Espectáculos, aunque ésta los hubiera nombrado asesores de la misma. Del suceso quedó constancia en un acta notarial emitida a instancia del letrado de la propiedad, D. Antonio Filpo (13). En la comunicación al gobernador Sr. Sanmartín, la junta le transmitió que se aplazaba la visita al siguiente jueves por no encontrarse las obras terminadas y debido a

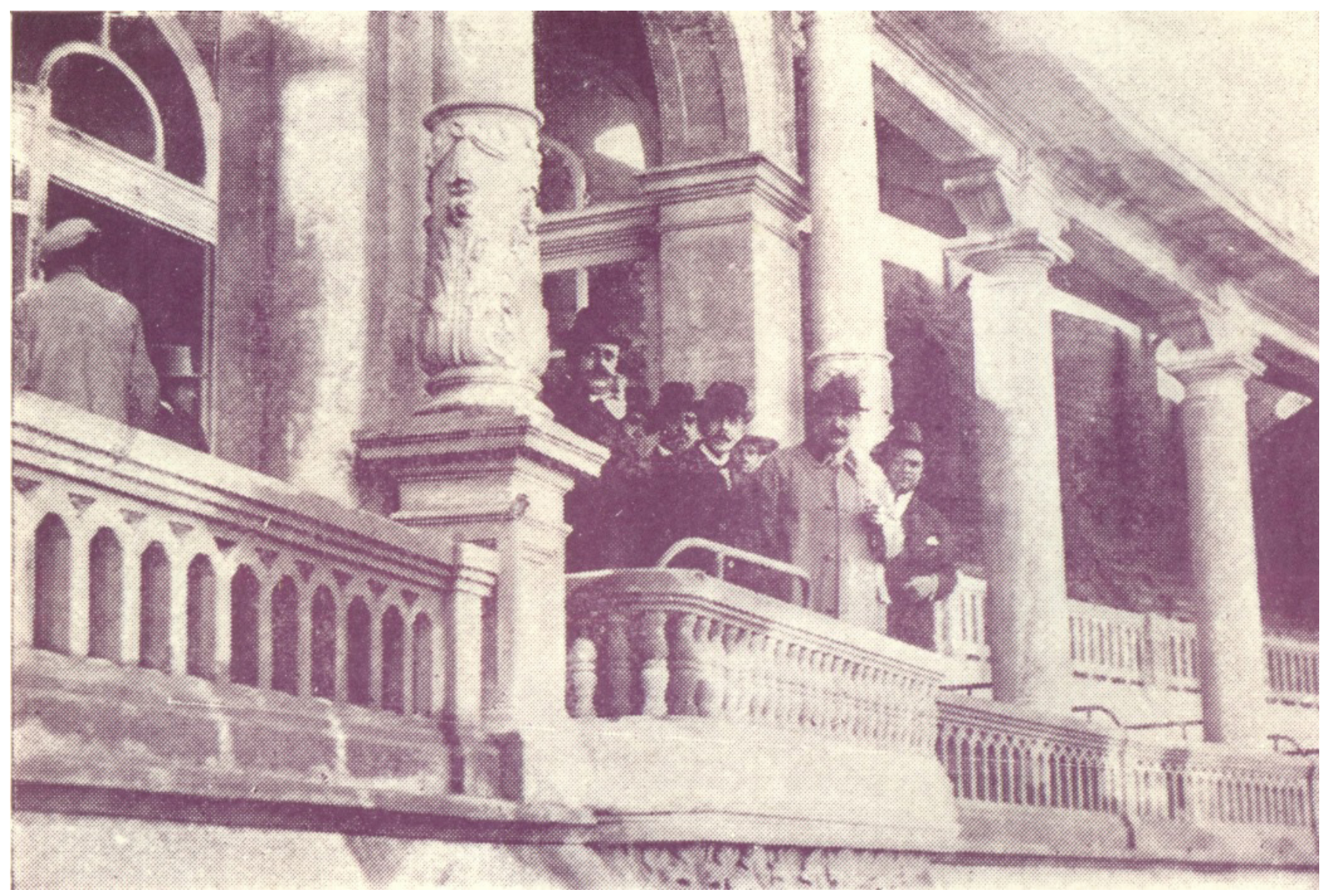

Figura 5. Un grupo de personas en el Palco Real de la Monumental. Seguramente se trata de una visita de la Junta Provincial de Espectáculos. Con gabardina clara aparece José Espiau. Enciclopedia Espasa, vol. 45, páginas 672-673. 
la oposición de la propiedad a la realización de las pruebas. En cuanto a la prueba de carga, pretendían dividir la plaza en cuarenta sectores, cargados con $500 \mathrm{~kg} / \mathrm{m}^{2}$, al menos durante 24 horas (14).

El 1 de abril El Correo de Andalucía publicó un comunicado en el que Francisco Urcola informaba del inicio de las pruebas de carga. Tal era su confianza en la solidez del edificio, que invitaba al director del diario a comprobar personalmente la ejecución de la prueba, dejando entrada libre para que el público «pudiera presenciar las experiencias». El 8 de abril aparecieron cuarteos en algunas columnas con el cedimiento de parte de la andanada y 10 de abril la prensa local reproducía el informe emitido por los técnicos que realizaron la prueba (15) (16), que finalmente fueron los señores Ramírez Doreste, Gómez Millán y Talavera Heredia. Para la prueba, la plaza se dividió en diez sectores, cargados con $500 \mathrm{~kg} / \mathrm{m}^{2}$ en proyección horizontal, mediante el empleo de sacos de arena y barras de plomo. Llama la atención que los técnicos hicieran constar la aparición de fisuras en pilares, sin hacer referencia a los resultados obtenidos en las vigas, cuando las pruebas de carga ya eran sobradamente conocidas en España. Tampoco consta la instalación de flexímetros, por lo que esta prueba de carga aparentemente carecía de garantías sobre su ejecución. La Tabla 1 muestra los datos reflejados en el informe de los técnicos.

En el sector 9 el informe deja constancia de la rotura por compresión de un pilar de 40x40 de los que sustentaban tendidos, gradas y andanadas, quedando a la vista las armaduras del pilar, presentando las verticales la convexidad hacia el exterior, considerándolo los propios técnicos un defecto de ejecución, por la inclinación que presentaban los estribos, que deberían ser horizontales. Las roturas por compresión se manifiestan en los pilares mediante fisuras verticales, lo que contrasta con la toma de datos de la Tabla 1, donde se hace mención a fisuras por aplastamiento en la base o en zonas cercanas al capitel. El hecho de que solamente se indique una cota, por ejemplo 0,12 m en el pilar 5 de la andanada del sector 7, parece indicar que eran fisuras horizontales, seguramente irrelevantes desde el punto de vista estructural. En base a los datos disponibles esta prueba de carga fue incorrecta, ya que no se midieron deformaciones, que es el fin de este tipo de ensayos, sino que los técnicos se centraron en los pilares, que son más favorables, ya que trabajan principalmente a compresión, lo que supone una situación óptima en elementos de hormigón. Antes de dañarse los pilares, deberían estarlo las vigas.

Al día siguiente de la visita de los técnicos, la plaza sufrió el hundimiento de parte de la estructura (Figura 6). El Correo de Andalucía y el Noticiero Sevillano publicaron la noticia del suceso el 11 de abril, afirmando que la zona afectada se extendía en más de un tercio de la estructura, desde el lado derecho de la puerta grande hasta la puerta de arrastre. Según la descripción, el hundimiento afectó escasamente a un cuarto de la estructura del edificio (Figura 7).

2.2.1. Posibles causas del hundimiento durante la prueba de carga de 1917

Varias pudieron ser las causas que motivaron este hundimiento de la plaza durante las pruebas de carga. En aquellos días la prensa local publicó numerosas noticias. En esta vorágine de noticias y rumores, destaca la publicación de algunos hechos en El Liberal, con una entrevista realizada al encargado de la empresa constructora que no se explicaba lo sucedido, pero consideraba que un edificio así «no puede caerse tan fácilmente» (17). En este sentido, El Noticiero Sevillano, reproduce una conversación en la que un supuesto perito en la materia, afirmaba que el problema se encontraba en que el hormigón se había elaborado con mucha arena. En el mismo artículo se indica que entre los operarios de la constructora, afirmaban que el hundimiento se debía a causas ajenas a la construcción, mientras que un miembro de la Comisión, no identificado, afirmaba que la construcción adolecía de defectos importantes (18).

Otro posible motivo para que se produjera el hundimiento fue el ritmo acelerado de la obra. El 14 de diciembre de 1916 el diario $\mathrm{ABC}$ publicó la noticia de un hundimiento ocurrido en la plaza el día anterior, coincidiendo con el temporal y al parecer motivado por la retirada prematura de los encofrados, destrozado la zona de los tendidos de sol donde se encontraban los chiqueros. En la figura 8 se ve en primer plano una losa adherida a su encofrado, así como numerosos restos de madera, por lo que quizás se retiró algún puntal, pero la estructura estaba encofrada cuando se produjo el hundimiento. El mismo diario publicaba unos días después (19) que el hundimiento había afectado a 15 tramos de tendido, ilustrando la noticia con una fotografía de la zona afectada, que coin-

Tabla 1. Datos de la prueba de carga efectuada en 1917. El Noticiero Sevillano. Martes 10 de abril de 1917, pág. 1.

\begin{tabular}{|c|c|c|c|c|}
\hline \multicolumn{5}{|c|}{ RESUMEN DE DATOS DEL INFORME DE LA PRUEBA DE CARGA EFECTUADA EN 1917} \\
\hline SECTOR & COLUMNA & $\begin{array}{l}\text { DISTANCIA } \\
\text { AL CAPITEL }\end{array}$ & COMENTARIO & DISTANCIA A LA BASE \\
\hline \multirow[t]{3}{*}{2} & 2 Andanada & $0,15 \mathrm{~m}$ & Rotura por aplastamiento & \\
\hline & 4 Andanada & $0,05 \mathrm{~m}$ & Rotura por aplastamiento & Fisura en la base de la columna \\
\hline & 6 Andanada & $0,50 \mathrm{~m}$ & Rotura por aplastamiento & Fisura en la base de la columna \\
\hline \multirow[t]{2}{*}{1} & 6 Andanada & & & Pequeña grieta en unión con base \\
\hline & 8 Andanada & $0,80 \mathrm{~m}$ & Indicio aplastam. Cara interior. & \\
\hline $10,6,5$ & & & Sin movimiento digno de mención. & \\
\hline \multirow[t]{2}{*}{7} & 6 Andanada & $0,90 \mathrm{~m}$ & $\begin{array}{l}\text { Rotura de la columna. Sin llegar a } 500 \mathrm{~kg} / \mathrm{m}^{2} \\
\text { se retira la sobrecarga. }\end{array}$ & \\
\hline & 5 Andanada & $0,12 \mathrm{~m}$ & Rotura por aplastamiento & \\
\hline 9 & $\begin{array}{l}\text { o,40xo,40 del anillo } \\
\text { de primera crujía }\end{array}$ & & $\begin{array}{c}\text { Tres columnas rotas en este sector de } \\
\text { andanada. }\end{array}$ & $1 \mathrm{~m}$ \\
\hline 3,4 y 8 & & & $\begin{array}{l}\text { No se habían cargado cuando se suspendió la } \\
\text { prueba. }\end{array}$ & \\
\hline
\end{tabular}




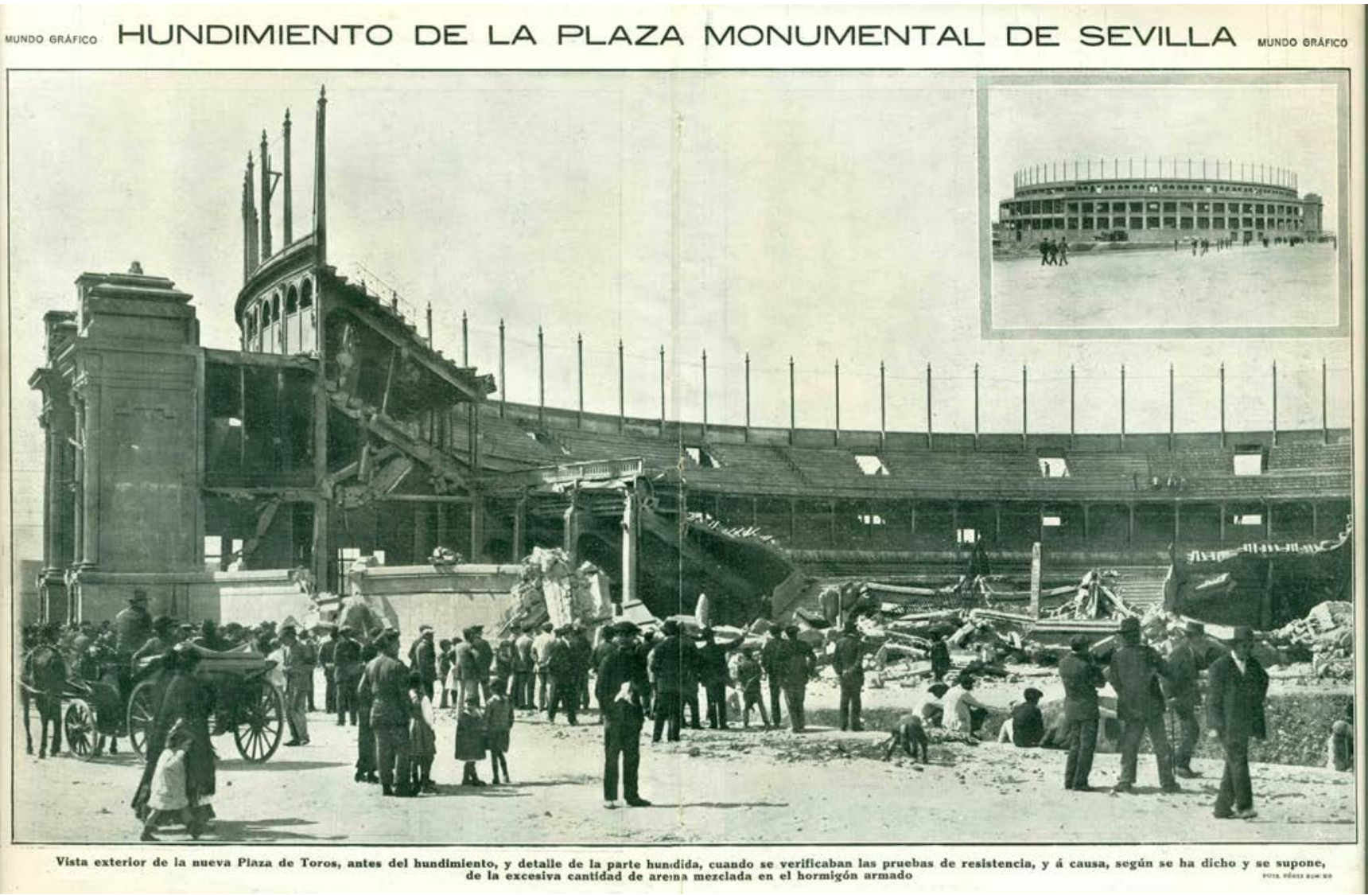

Figura 6. Imagen publicada a doble página en Mundo Gráfico el 18 de abril de 1917. Colección de los autores.

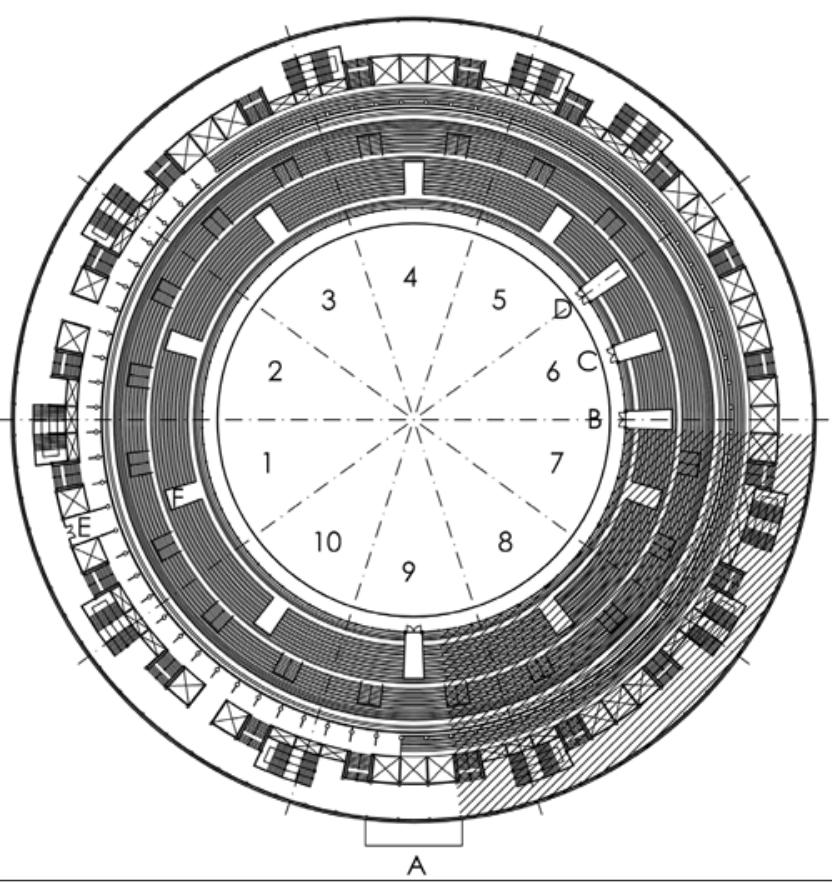

AVENIDA DE EDUARDO DATO

Figura 7. Planta de la Monumental. Se ven las cuatro puertas que se abrían al ruedo: la principal (A), la de arrastre (B), la de toriles (C) y la de cuadrillas (D). Enfrente de la puerta de toriles se encontraban el palco real (E) y la presidencia (F). Los números corresponden a los sectores de la carga y la zona sombreada a la afectada por el hundimiento ocurrido durante las pruebas de 1917, según la descripción publicada en varios diarios. La numeración de sectores no corresponde con la de los tendidos, que eran 11 cide aproximadamente con los sectores 6 y el 7 de la prueba de carga de 1917. En el informe de los técnicos se indica que en el sector 7 se produjo la rotura de la columna 6 de la andanada, sin llegar a la carga de $500 \mathrm{~kg} / \mathrm{m}^{2}$. El Día publicó una imagen prácticamente igual el 16 de diciembre de 1916 y otras aparecieron en la revista Toros y Toreros (Figura 8). Del análisis de estas imágenes y la figura 2 de este documento, se deduce que la obra debió iniciarse en la avenida de Eduardo Dato (entonces Monterrey), siguiendo el sentido horario. En la figura 2 se aprecia en primer término una columna de la grada, la puerta principal en el ángulo inferior derecho de la imagen y las puertas de cuadrillas y de toriles en el superior derecho. Arriba a la izquierda se ve que se está disponiendo el encofrado de la grada entre los sectores 3 y 4, sobre las vigas inclinadas previamente construidas. Teniendo en cuenta que a mediados de diciembre de 1916 se hundieron parte de las gradas y que faltaban por construir las andanadas en al menos la mitad de la plaza que se ve en las fotografías, parece poco probable que la obra finalizase entre enero y febrero de 1917, para respetar el plazo recomendable de entre un mes y medio y dos meses, para iniciar las pruebas de carga antes de la inauguración prevista para el 1 de abril. Todo apunta a que al menos este tramo final de la obra se realizó apresuradamente, quizás por los plazos comprometidos con la propiedad, que en marzo de 1917 publicó en prensa los precios de las localidades de la plaza de toros Monumental (20). Lo normal es que el último tramo de plaza construido fuera el afectado por este derrumbe, que coincide con los sectores 6 y 7. Siguiendo el sentido horario de la construcción, el último en construirse sería el sector 7 , donde los técnicos dejaron constancia de que la columna 6 de la andanada colapsó antes de aplicar la totalidad de la carga prevista (Tabla 1). Es decir, 


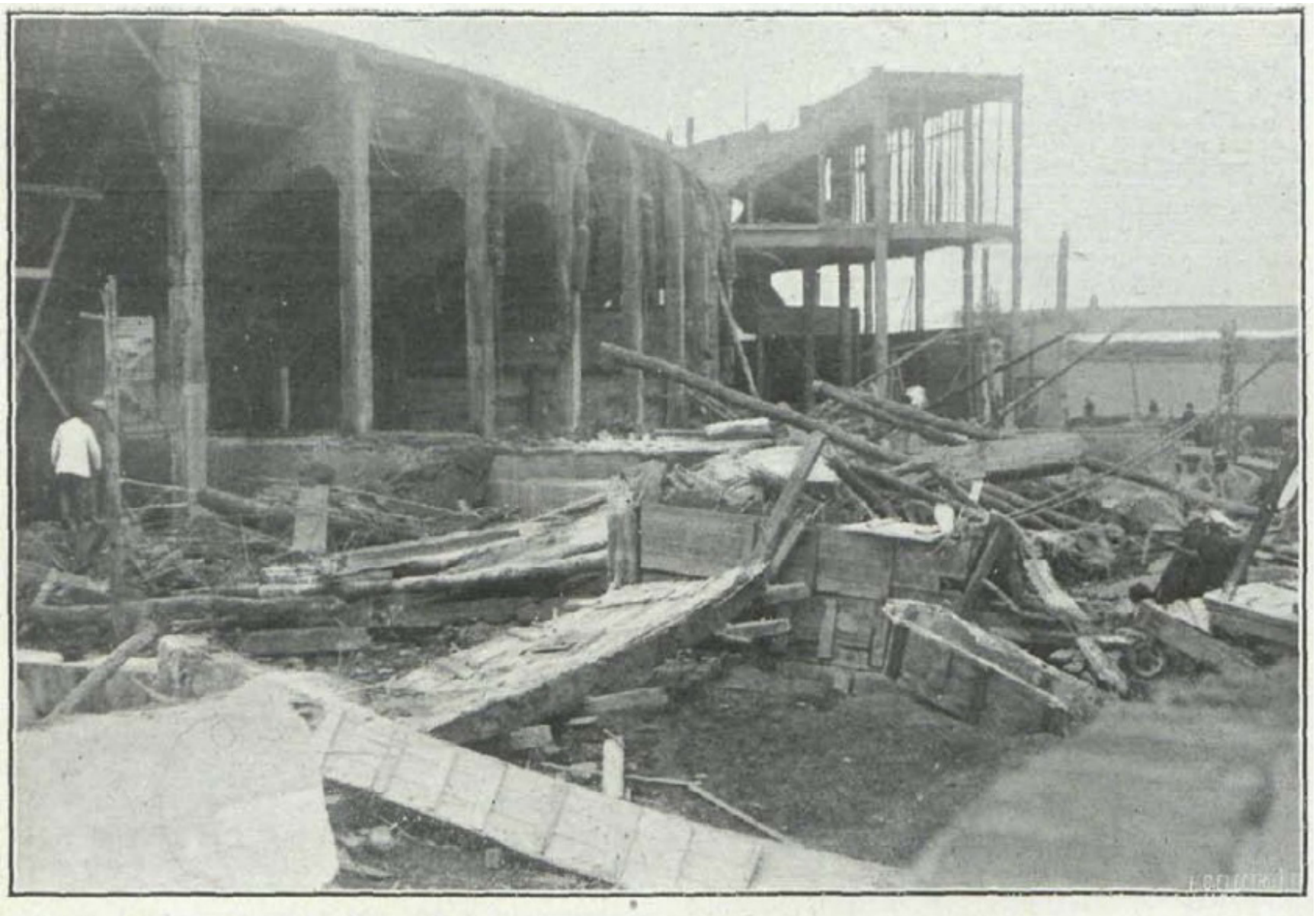

ASPEOTO DEL DERHUMBAMIENTO EN UNA PARTK DK LOS TKNDIDOS DK 801 ,

Figura 8. Imagen publicada Toros y Toreros el 16 de diciembre de 1916. Biblioteca Nacional.

parece que la decisión de realizar la prueba de carga fue precipitada.

También cabe la posibilidad de que se produjera un sabotaje, si atendemos a algunos detalles publicados, como el referido al rumor de que los obreros encargados del desescombro habrían encontrado en un profundo hoyo restos de algunos petardos, «lo que confirmaría el carácter intencionado del hundimiento» (21). Esta noticia aislada puede ser una conjetura más, pero podría estar relacionada con el relato del hundimiento publicado en otro artículo de El Noticiero Sevillano, en el que se afirma que «El hundimiento fue rapidísimo y simultáneo, y de su violencia daban idea los grandes trozos de cemento que se encontraban a muchos metros de distancia de los muros de la plaza» (22), especialmente si observamos que en la imagen publicada en Mundo Gráfico (Figura 6) se ve que la plaza se hundió hacia el interior, por lo que la noticia puede ser fruto de una exageración más, o de que el hormigón fuera desplazado a muchos metros de distancia como consecuencia de una explosión.

\subsection{Prueba de carga de 1918. Realizada por Zafra y Gato}

Una vez reconstruida la plaza se realizó una segunda prueba de carga bajo la dirección del ingeniero jefe, profesor de la Escuela de Caminos, Juan Manuel Zafra y el arquitecto, profesor de la Escuela superior de Arquitectura, Carlos Gato Soldevilla. La operación se realizó entre el 20 de marzo y el 8 de abril de 1918 (23), cargando los tendidos con arena, que se fue desplazando por los sectores de la prueba. En esta ocasión se colocaron flexímetros (Figura 9) para medir la flecha de cada una de las seis vigas de cada uno de los ochenta tramos, lo que supuso un total de 480 lecturas. Además se realizaron 120 mediciones en las escaleras. La carga adoptada fue de $600 \mathrm{~kg} / \mathrm{m}^{2}$, lo que suponía aumentar una vez y media la carga de proyecto, según las evaluaciones realizadas por los propios técnicos. Es decir, se respetaron los criterios habituales para este tipo de edificios, conforme a los artículos 32 a 39 de las «Instrucciones reglamentarias para el empleo del cemento armado». La Tabla 2 resume los resultados obtenidos.

Los técnicos finalizaban su informe afirmando que las deformaciones por flexión habían sido «desde luego suficientemente pequeñas y en su totalidad perfectamente elásticas».

Esta segunda prueba de carga fue realizada por dos expertos en la materia, siendo Juan Manuel de Zafra un precursor del uso del hormigón armado, que empezó a utilizar en el Puerto de Sevilla, tras finalizar sus estudios en 1892. Fue un teórico del hormigón armado, con numerosas publicaciones científicas al respecto, entre la que destacaba «Construcciones de hormigón armado» (1911). De los resultados reflejados en el cuadro resumen anterior se deduce que la prueba se realizó con el debido rigor, respetando tanto la normativa como el modo habitual de proceder en este tipo de ensayos, midiendo flechas. Con esta garantía resulta difícil entender que esta 


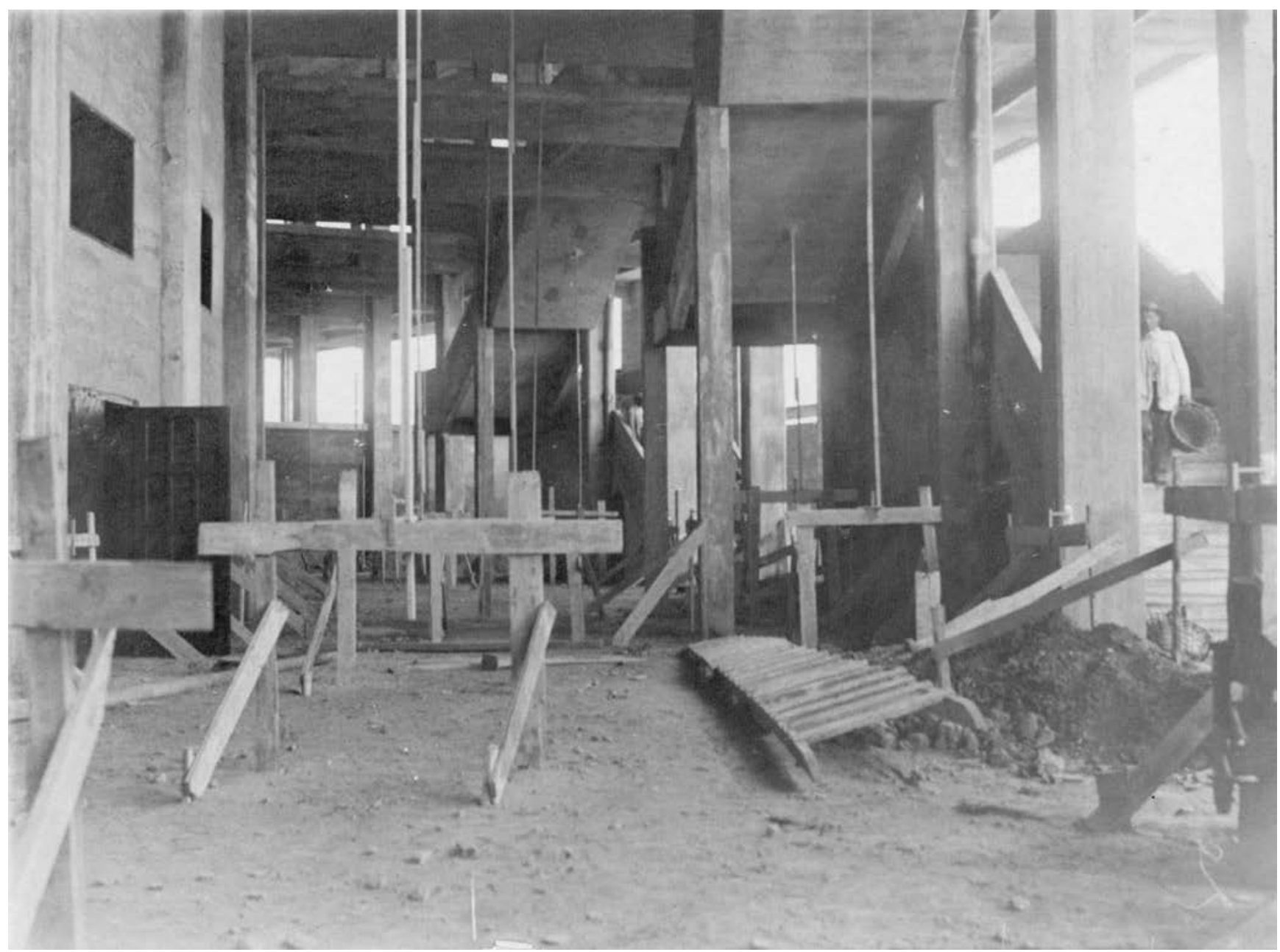

Figura 9. Aspecto de los flexímetros dispuestos para medir deformaciones durante la segunda prueba de carga, efectuada entre el 20 de marzo y el 8 de abril de 1918. Los dispositivos están compuestos por caballetes de madera fijados al suelo y una pértiga colgada del techo. Fundación FIDAS, Archivo Espiau, ref.: 2/00095 E02/3.

Tabla 2. Datos de la prueba de carga efectuada en 1918. La Construcción Moderna, $\mathrm{n}^{\circ}$ 10, pág. 114, 30 de mayo de 1918.

\begin{tabular}{|c|c|c|}
\hline \multicolumn{3}{|c|}{ RESUMEN DE DATOS DEL INFORME DE LA PRUEBA } \\
DE CARGA EFECTUADA EN 1918
\end{tabular}

plaza tuviera problemas estructurales tan sólo tres años después, como se comenta en el siguiente apartado.

\section{LA CLAUSURA DEL EDIFICIO}

El recinto funcionó sin ningún problema durante las temporadas de 1918, 1919 y 1920 . La temporada de 1921 no se celebró, a pesar de estar programada, al ser clausurado el recinto por supuestos problemas de seguridad estructural.

Efectivamente, el 8 de abril de 1921 el diario La Unión publicó la noticia de que el arquitecto señor Balbuena, el ingenie- ro señor Estrada y el doctor señor Laborde habían pasado al señor Elio un informe acerca del estado de la plaza de toros Monumental, en el que se hacía constar que casi todas las vigas inclinadas que servían de apoyo a las andanadas y los tableros de estas andanadas, se notaban partidos en sentido radial, lo mismo que en las gradas y tendidos, así como en los tabiques de cerramiento, galerías, cierres de escaleras y puerta principal. También se indicaba la existencia de filtraciones por aguas de lluvias en las andanadas. El informe finaliza afirmando que «los que lo suscriben no pueden dictaminar con suficiente garantía sobre la resistencia de la plaza».

En la página 4 del mismo diario, se indica que el gobernador civil reunió a la Junta de Espectáculos, para tratar el dictamen emitido por los técnicos acerca del estado de la plaza de toros Monumental, ordenando que no se celebrasen en la citada plaza ninguna clase de espectáculos. En la misma página se incluye un hiriente artículo en el que se afirma que «esa plaza, hecha de pan mascao, no podía sostenerse mucho tiempo en pie».

Dos días después el mismo diario daba la noticia de una visita al gobernador del propietario de la plaza, el arquitecto Espiau y el abogado Valentín Gamazo, anunciándole la presentación de un escrito solicitando la realización de nuevas pruebas de carga. El escrito fue presentado por el Sr. Espiau al día siguiente y el 1 de mayo el diario La Unión informaba de la 
reunión de la Junta provincial de Espectáculos, bajo la presidencia del gobernador, acordando desestimar la petición de la propiedad.

Entre los motivos de esta clausura se encuentran los económicos, ya que en la Monumental solamente se celebró la Feria de Abril en 1919 y 1920. En 1919 cada plaza programó sus carteles, siendo más económicos los precios de la Monumental. En 1920, la empresa de la Maestranza llevó ambas plazas y los precios fueron idénticos, celebrándose tres corridas en cada recinto. El 10 de abril de 1921 La Unión publicaba los carteles de feria en la Maestranza, con unos precios un 25\% superiores a los del año anterior. Sirva como ejemplo la primera fila de barrera de sombra, que pasó de 24 a 30 pesetas, localidad que para la temporada frustrada de 1917 se anunciaba a 15 pesetas en la Monumental.

\section{TRABAJOS DE DEMOLICIÓN DE LA PLAZA}

En la solicitud de licencia de demolición de 10 de abril de 1930 (24), se indica que la «operación se efectuará utilizando máquinas pneumáticas, herramientas ordinarias y pequeños petardos de dinamita al solo objeto de quebrantar los bloques de hormigón de los pies derechos.»

Del análisis de la figura 10 se deduce el procedimiento utilizado en la demolición de las andanadas de la plaza de toros Monumental, que aproximadamente fue el siguiente:

En primer lugar, se procedió al corte de los planos inclinados de la andanada, marcando líneas de corte radiales a la izquierda de los pórticos, según se mira la fotografía (flechas rojas). Posteriormente se debilitaron los arranques de las columnas, picándolas en su parte inferior (círculos).

El proceso terminaba con el uso de sogas o cables para volcar las columnas hacia los tendidos, tirando de su parte superior desde el ruedo (flechas naranjas). Entonces las andanadas caían sobre las gradas.

En la imagen se aprecia que en la zona de toriles (puerta central), se habían realizado cortes en el tendido alto, que no se derrumbó a pesar de haber sufrido el impacto de la caída de las columnas.

Hay quien considera que el estado de la estructura era ruinoso en 1930. A ello ha podido colaborar un leve error documental en el Archivo Municipal ICAS-SAHP, que fija la fecha de la figura 11 en 1930 (en el libro de Lourdes Ramos Kuethe se data en 1929-1930), sin hacer referencia a que está tomada durante los trabajos de demolición, siendo la fotografía posterior a la figura 10, fechada en abril de 1930 . En ambas imágenes se aprecian tres de las cuatro puertas que se abrían al ruedo, siendo de izquierda a derecha, la de cuadrillas, la de toriles y la de arrastre. En la figura 11 se ve que la andanada había desaparecido, faltando también los tendidos y la grada en la parte situada por detrás de las puertas. La figura 10 es sin duda de una fecha anterior, correspondiente al momento en el que acababan de demolerse las andanadas de esta zona, pues se ven algunos restos de las mismas sobre la grada, además de las columnas sobre los tendidos.

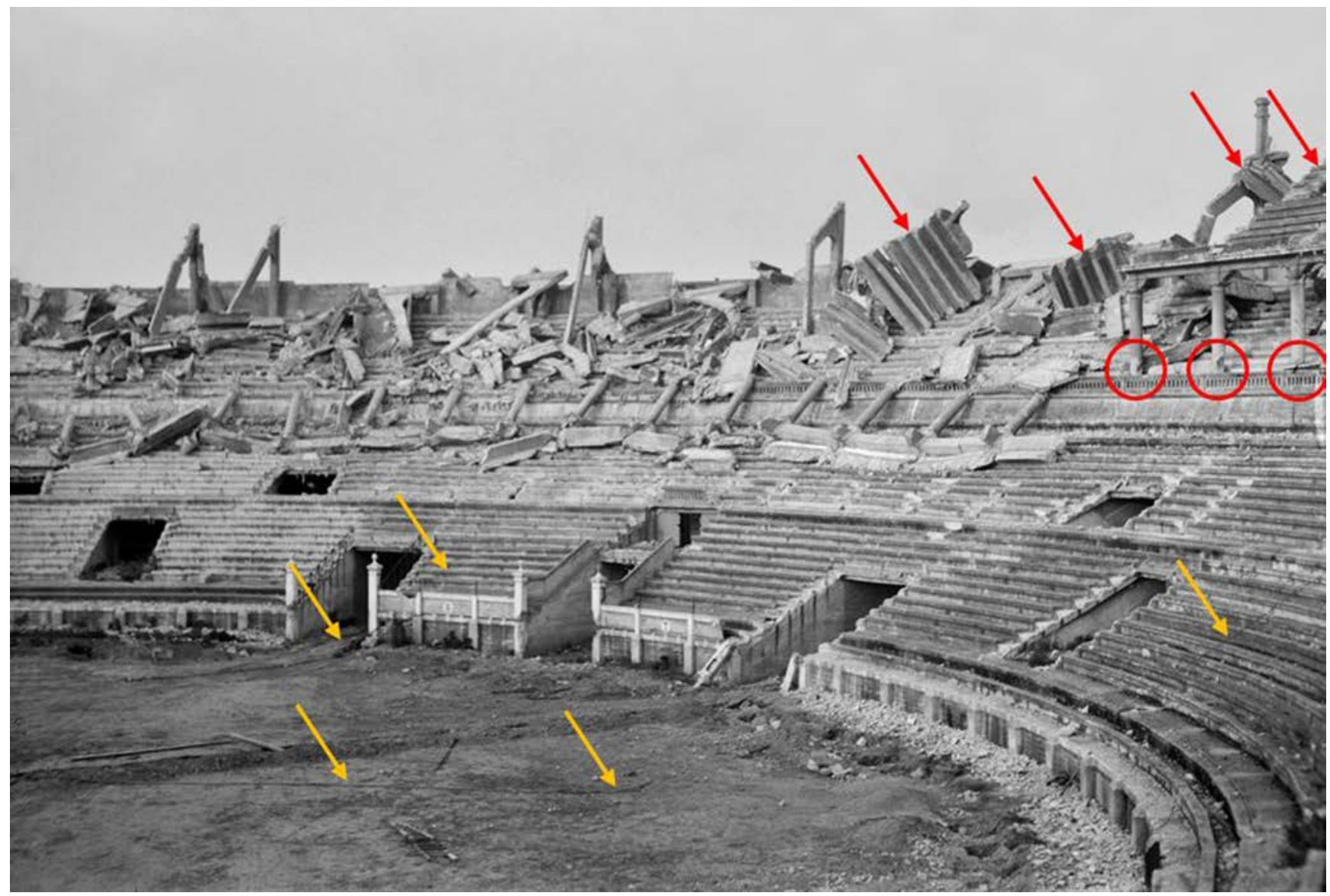

Figura 10. Juan José Serrano. Trabajos de demolición de la plaza de toros Monumental. Vista del ruedo y los tendidos. Abril de 1930. (C)ICAS-SAHP, Fototeca Municipal de Sevilla, Archivo Serrano. 
En relación con lo anterior, indicar que existen varias fotografías aéreas de Sevilla en las que se ve la plaza de toros completa, es decir, con las andanadas. Aunque sea de poca calidad, sirva como ejemplo la figura 12, que es una vista tomada desde la Giralda, en la que se aprecia el mercado de la Puerta de la Carne, edificado entre 1927 y 1929 (25) y al fondo la Monumental, con la andanada.

\section{CONCLUSIONES}

El presente artículo recopila, ordena y relaciona documentación dispersa relativa a la plaza de toros Monumental de Sevilla, centrando la información en los aspectos relativos a las pruebas de carga realizadas, técnica habitual en la época para validar las estructuras. En el caso de la Plaza sevillana debieron realizarse dos pruebas, las primeras en 1917, cuyos resultados no fueron satisfactorios y otras al año siguiente.
Efectivamente, durante las pruebas de 1917 se produjo un hundimiento parcial, aparentemente asociado a que fueron realizadas con la obra recién terminada, sin respetar el plazo necesario para acometerlas con seguridad, al no haber alcanzado el hormigón su resistencia total. Además, el informe técnico es anómalo, ya que refleja fisuras en pilares, pero no deformaciones en vigas, que son los elementos más sensibles y que ya entonces centraban la atención en este tipo de ensayos. Seguramente el hundimiento de la plaza se produjo por la suma de ambas causas, pudiendo incluso haber sido objeto de un sabotaje.

La propiedad consiguió que la prueba de carga de 1918 la realizaran dos técnicos de gran prestigio, especialmente el Ingeniero Zafra, el mayor experto en hormigón armado en España. En este caso se midieron deformaciones en vigas, llegando a la conclusión de que la estructura era segura.

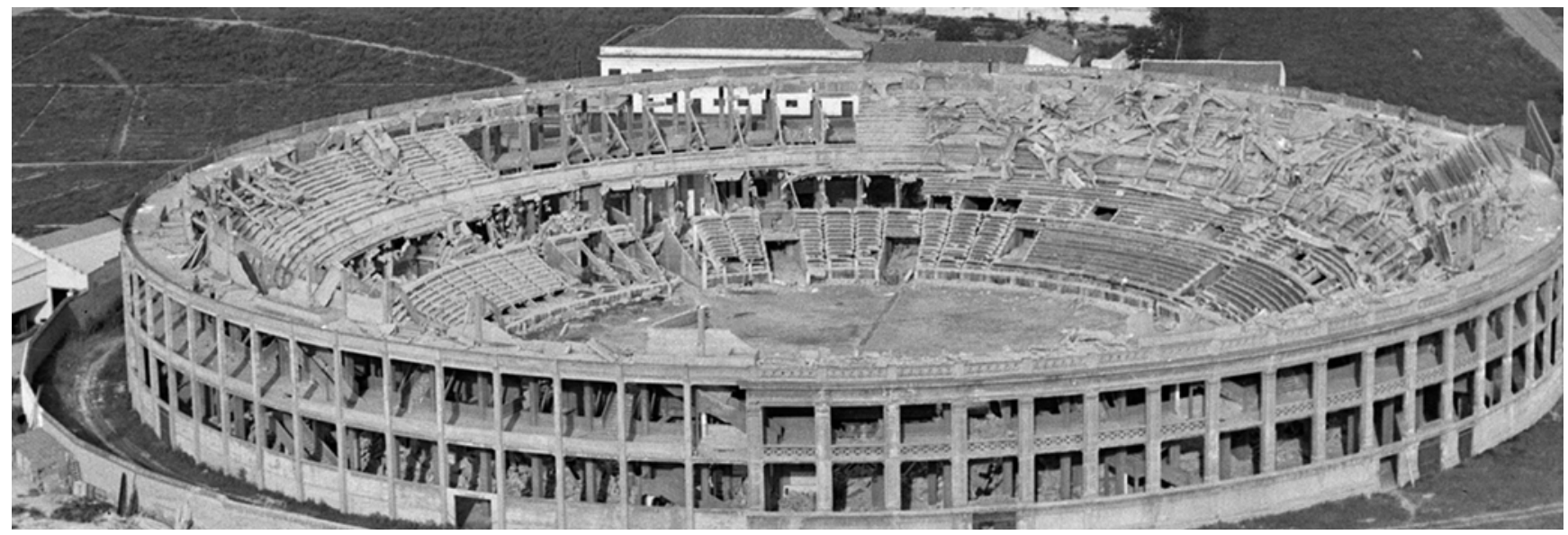

Figura 11. Detalle de la vista aérea de la Monumental. 1930. (CICAS-SAHP, Fototeca Municipal de Sevilla, Archivo Sánchez del Pando.

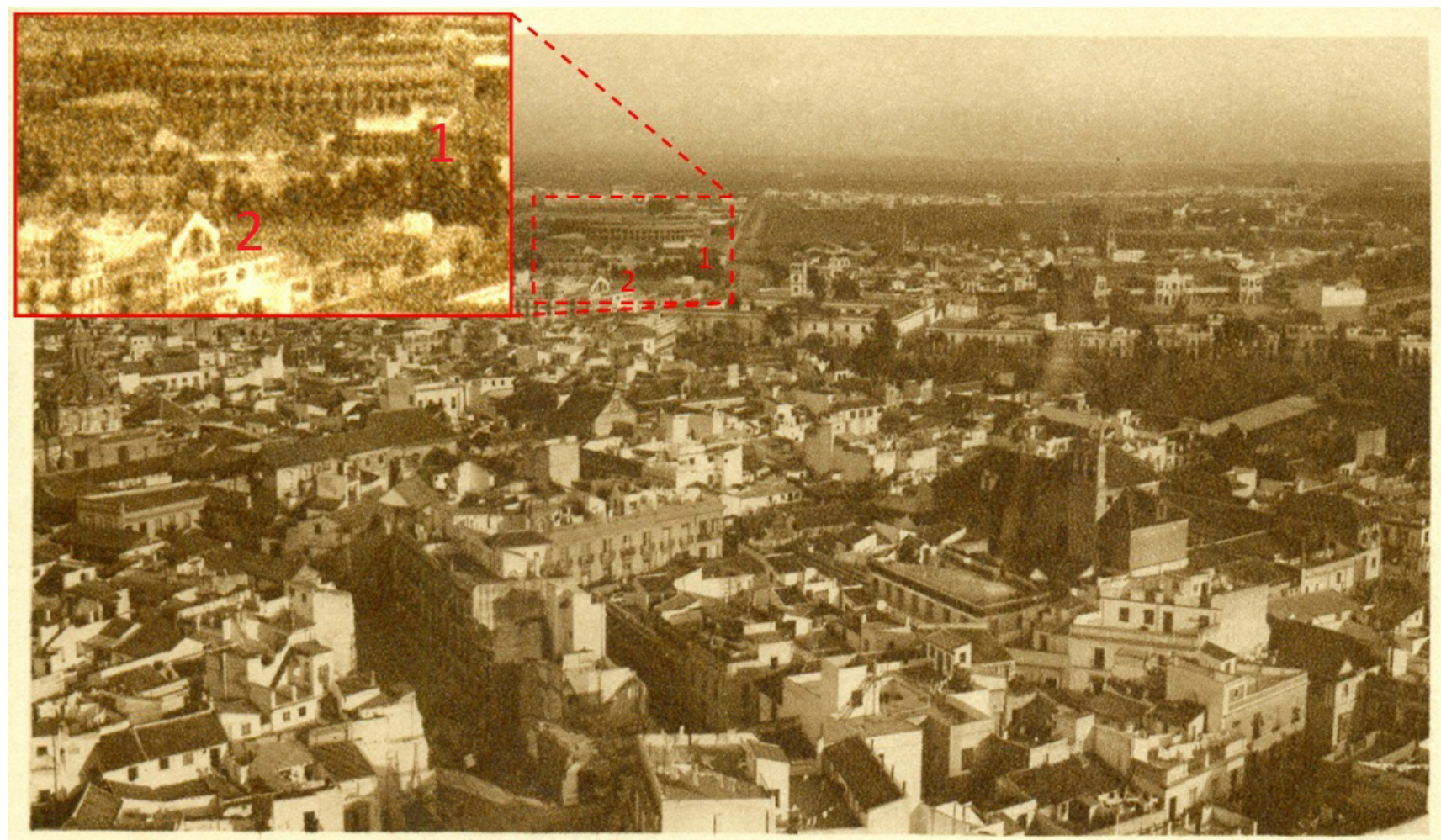

SEVILLA - Vista panorámica.

Figura 12. Tarjeta postal. Se ven la Monumental (1) y el mercado Puerta de la Carne (2). Colección de los autores. 


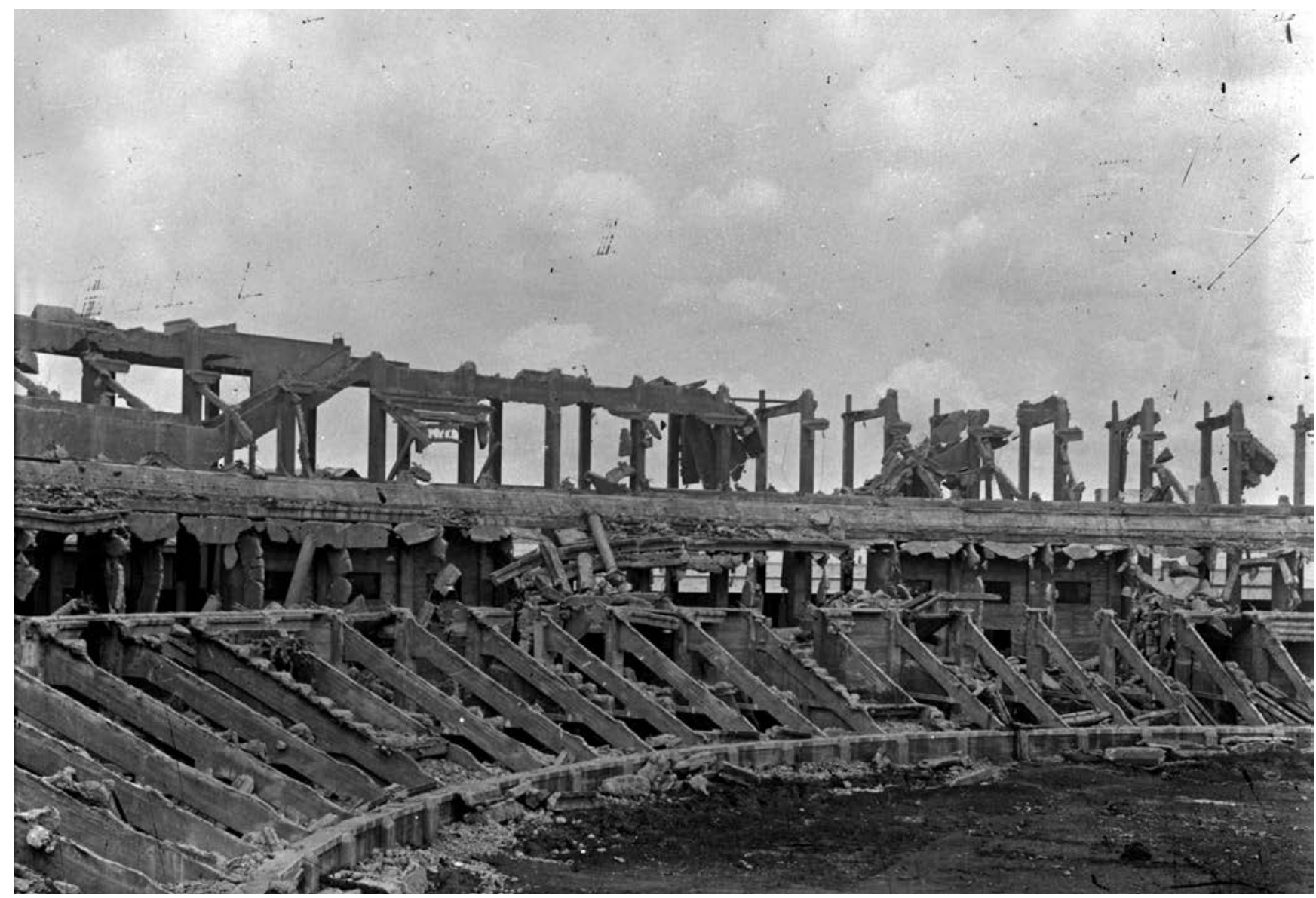

Figura 13. Juan José Serrano. Trabajos de demolición de la plaza de toros Monumental. Abril de 1930. CICAS-SAHP, Fototeca Municipal de Sevilla, Archivo Serrano.

Tras apenas tres temporadas en servicio, resulta difícil entender que esta plaza fuera clausurada en 1921 por supuestos problemas estructurales, en base a la inspección visual realizada por los técnicos de la Junta provincial de Espectáculos, negando el gobernador la posibilidad de que se realizaran nuevas pruebas de carga, solicitadas por la propiedad. Ello condujo a que se decidiera demoler la plaza en 1930, como se muestra en la figura 13.

Con este trabajo se pretende contribuir a dilucidar el misterio que rodea a la Monumental de Sevilla, ya que los datos, aunque escasos y dispersos, permiten determinar que la plaza tuvo un comportamiento aparentemente satisfactorio durante los tres años que se mantuvo en servicio. Sólo en dos de las tres temporadas mantuvo competencia con la Maestranza. En 1920, la empresa de la Maestranza llevó el negocio en ambos recintos, con idénticos precios. A pesar de estar programada, la temporada de 1921 no se celebró. Quizás tenía razón Fernando López Vilches al afirmar: «fuertes presiones, procedentes de muy altas esferas, fueron en realidad, la falta de solidez de este magnífico coso» (26).

\section{REFERENCIAS}

(1) Sonseca Rojas, Ángel. (2008) El cartel taurino, la sociedad y los toros (1820-1920). Tomo II. p.381. Madrid.

(2) Ramos-Kuethe, Lourdes. La monumental de Sevilla. Voces y silencios. (2011). p.72. ICAS-Ayuntamiento de Sevilla.

(3) López Izquierdo, Francisco. Madrid y sus plazas de toros. (2008) p.21, 29. Ediciones La Librería. Madrid.

(4) Real Maestranza de Caballería de Sevilla (2014). Historia de la construcción de la Real Plaza. http://www.realmaestranza.com/plaza_de_toros/La_plaza/Historia_de_su_construccion-ides-idhtml.html

(5) CEDEX-CEHOPU (2010). Hormigón Armado en España 1893-1936. http://www.cehopu.cedex.es/hormigon/fichas/ img_ficha.php?id_img=77

(6) Marcos, I., San José, J.T., Cuadrado, J., Larrinaga, P. (2014). Las patentes en la introducción del hormigón armado en España: caso de estudio de la Alhóndiga de Bilbao. Informes de la Construcción, 66 (534): eo24, doi:http://dx.doi. org/10.3989/ic. 13.032.

(7) Díaz-Pavón Cuaresma, E. Investigación sobre las causas que pudieron originar el hundimiento de la cubierta del tercer depósito del Canal de Isabel II en 1905. Tesis doctoral. UPM 2015.

(8) Burgos Núñez, A. Los orígenes del hormigón armado en España (2009). Ministerio de Fomento.

(9) Compañía Anónima del Hormigón Armado Sestao-Bilbao. (1902). Nota sobre las construcciones de hormigón armado. La Poutre Dalle. Sistema Blanc. Bilbao: Imprenta Antonio Apellaniz. 
(10) La Construcción Moderna. Instrucciones Reglamentarias para el empleo del cemento armado. 15 de junio de 1912. Año $\mathrm{X}, \mathrm{N}^{0} 11$. p.159-172. Madrid.

(11) ABC. 14 de diciembre de 1916. p.18. Madrid.

(12) Villar Movellán, Alberto. (1985). Arquitecto Espiau. p.42. Diputación de Sevilla.

(13) El Correo de Andalucía. Año XIX. Nº6392. p.1. 27 de marzo de 1917. Sevilla.

(14) El Correo de Andalucía. 27 de marzo de 1917. p.1-2. Sevilla.

(15) El Noticiero Sevillano. Año XXV. N9464. 10 de abril de 1917. p.1. Sevilla.

(16) El Correo de Andalucía. 10 de abril de 1917. Sevilla.

(17) Ramos-Kuethe, Lourdes. La monumental de Sevilla. Voces y silencios. (2011). p.201. ICAS-Ayuntamiento de Sevilla.

(18) El Correo de Andalucía. 10 de abril de 1917. El hundimiento de la plaza Monumental. Sevilla.

(19) ABC. 17 de diciembre de 1916. p.4. Madrid.

(20) El Correo de Andalucía. 24 de marzo de 1917. Sevilla.

(21) La Época. Año LXIX. $\mathrm{N}^{0}$ 23.938. 9 de junio de 1917. p.4. Madrid.

(22) El Noticiero Sevillano. Año XXV. No 9464.10 de abril de 1917. p.3. Sevilla.

(23) La Construcción Moderna. El hormigón armado en España. Pruebas de resistencia en la nueva Plaza de Toros de Sevilla. 30 de mayo de 1918. Año XVI, No10. p.112-118. Madrid.

(24) Ramos-Kuethe, Lourdes. La monumental de Sevilla. Voces y silencios. (2011). p.118. ICAS-Ayuntamiento de Sevilla.

(25) http://sig.urbanismosevilla.org/Sevilla.art/SevLab/eDo12_files/eDo12.pdf

(26) Fernando López Vilches, Abel Infanzón. Joselito el Gallo, la Monumental y su extraña ruina. ABC Sevilla. 1 de mayo de 1984 .

(27) Carrasco Andrés, F., Carrasco Andrés, J., del Castillo Rodríguez, C. (marzo de 2018). Los inicios del hormigón armado en España: Francisco Urcola y tres edificios singulares. Revista DYNA, 94: 160-164, doi: http://dx.doi.org/10.6036/8610. 